\title{
An Empirical Study of Face-to-Face and Distance Learning Sections of a Core Telecommunication course
}

\author{
Omaima Almatrafi, George Mason University \\ Dr. Khondkar Islam \\ Dr. Aditya Johri, George Mason University
}

\begin{abstract}
Aditya Johri is Associate Professor and Chair in the Applied Information Technology Department. Dr. Johri studies the use of information and communication technologies (ICT) for learning and knowledge sharing, with a focus on cognition in informal environments. He also examine the role of ICT in supporting distributed work among globally dispersed workers and in furthering social development in emerging economies. He received the U.S. National Science Foundation's Early Career Award in 2009. He is co-editor of the Cambridge Handbook of Engineering Education Research (CHEER) published by Cambridge University Press, New York, NY. Dr. Johri earned his Ph.D. in Learning Sciences and Technology Design at Stanford University and a B.Eng. in Mechanical Engineering at Delhi College of Engineering.
\end{abstract}

Mr. Karthik Nagappan, George Mason University

Mr. Aref Modanlu, George Mason University

Graduate Research Assistant 


\title{
An Empirical Study of Face-to-Face and Distance Learning Sections of a Core Telecommunication course
}

\begin{abstract}
We present an empirical study that compared the student learning outcomes of face-to-face and distance learning sections of a Telecommunications course. Student performance was assessed based on the course grade, which included the final exam, quizzes, assignments, and midterm exam scores. Both classes were taught by the same instructor, and had similar content and assessment measures. The study factored in the students' demographics such as gender, work and residency status to assess their impact on student learning. In addition, data stored in the learning management system (LMS), BlackBoard ${ }^{\mathrm{TM}}$, were collected and used to understand student activities within the system, and determine their relation with student performance. The number of times the material was accessed and the time duration spent on assessments are some of the examples of the data that were included in the study. The results show that there is a correlation between students' use of Blackboard and student performance. We found a significant statistical difference between course grades of the face-to-face and distance learning sections. We did not find any evidence for significant difference across a range of demographic factors.
\end{abstract}

\section{Introduction}

Over the years, as the available technologies and student demographics [6] have changed, higher education institutions have begun offering more and more distance education (DE) classes to their students. According to [2], the number of students taking at least one online class was about 6.7 million in 2012, which is more than $30 \%$ of total enrollment. Although research on distance learning (DL) has been conducted since its early adoption, there are few comparative studies between distance and face-to-face (F2F) classes. As institutions increase their offerings of online courses they often face the challenging task of finding the right balance between face-to-face and online offerings and therefore it is important to understand the issues across a range of courses and contexts.

In this study we compare two sections of the same course offered in the same semester. Both two classes used a learning management system (LMS) called Blackboard $^{\mathrm{TM}}(\mathrm{BB})$ to facilitate content delivery, store assignments, send announcements, create discussion forums, and manage grades. BB is the official LMS of the institution and is used by instructors to upload the course materials (e.g. lecture slides, lecture and lab videos for the distance learner, syllabus, etc.), conduct quizzes, and communicate with the students. Students used it to download and submit their assignments, complete the quizzes, access course materials, and see their grades.

In this paper, section 2 is a literature review of online and face-to-face class comparisons. We describe our study in section 3 where we elaborate on the data and methods used. Section 4 analyzes the data and reports the results of data 
analytics. Section 5 is on conclusion and future directions that concludes our findings, and recommends changes and modifications in subsequent studies for future research.

\section{Literature review}

For more than two decades, online and F2F education has been of rising interest among researchers, including in engineering [1], because of the significant progress distance education has made in the practical arena. Many of the studies done so far have focused on academic performance measurement to gauge the differences between online and F2F learning, and to assess student satisfaction with the course [11].

An extensive review [8] summarizes the efficacy of the outcomes of online and F2F education. The review involved 355 comparative studies and raised what's known as "No Significant Difference" phenomena. Russell concluded there is no significant difference between online and traditional classroom education outcome. However, his results were criticized for several reasons [3]. The review included some studies of low quality, without qualification. In addition, it accepted the null hypothesis, which does not deny the existence of the difference, where the sample does not include studies with significant difference.

Another meta-analysis [5] reviewed 73 studies that compared online and traditional education during 1992-2002. This meta-analysis shows half of the studies found no significant difference between online and F2F learning outcomes. Interestingly, most of the remaining studies show distance learning students outperform their counterparts of F2F learning environment. It also reports more than half of the studies, which compared student satisfaction with the course, found F2F students are more satisfied with the course in comparison with the online students. In summary, distance learning is as effective as face-to-face learning considering student performance with exams. Another meta-analysis for the period (1996- July 2008) also confirmed that on average students in online settings do better than students in F2F class [7]. However, more recent study [12] indicates that there is a significant difference in overall student performance between F2F and distance education sections. Students taking the course in F2F section have a better performance, but the study does not specify the course being taught.

Bernard et al. [3] conducted a meta-analysis comparing F2F and DL courses, but in their study the DL courses were split into synchronous and asynchronous classes. Synchronous classes require students to be available at specific times to watch streamed lecture videos and participate in live discussions. Asynchronous classes allow students to access the class materials at their convenience. The analysis reported that students in F2F classes outperform the synchronous DL students. However, asynchronous online classes outperform F2F classes.

In a recent study, academic leaders were asked to rate the online learning outcomes. The survey reported $77 \%$ of academic leaders believe distance education 
outperform face-to-face education. This is a major shift from the survey done on 2003 where only $57.2 \%$ of academic leaders perceived the same [2].

Many studies have compared the effectiveness of DL and traditional F2F classes [3, $5,9,12]$. But, most encountered methodological weaknesses such as small nonrandom samples, lack of factoring demographic variables, and substantial differences in course materials and assessments [4, 12]. To address these shortcomings, the objective of our study was to compare student outcomes of a F2F web-facilitated class and an asynchronous DL class of a core Modern Telecommunication undergraduate course. We factored in demographics data using identical materials and assessments of both sections.

\section{Research Study}

This empirical study involved two classes. The first class was a web-facilitated F2F course where students met in a classroom during the scheduled class time. It used BB LMS to accommodate a segment of online learning that facilitated course material access, and communication with the instructor and classmates. The second class was an online course. Here most the activities like accessing the materials, watching the lectures, completing the assessments, etc. was done online. The class did require the students to meet face-to-face in a classroom on campus two times a semester to take the midterm and the final exams. Both sections were taught by the same instructor and used the same type of assessments. Both sections had similar enrollment of 34 students each, but their demographics were different. Table 1 summarizes the demographic data of each section.

We defined the type of classes in the study based on the definitions stated in the BSRG report. There are four different types of courses categorized based on the proportion of content delivered online: 1. Traditional course, where there is no technology involved in the content delivery; 2. Web-facilitated course, where technology is used $1 \%-29 \%$ of the course to facilitate content delivery with the use of some type of learning management system. However, most of the course is conducted face-to-face; 3 . Hybrid course that entails $30 \%-79 \%$ of the course delivery to be online. Typically, hybrid courses offer blended F2F and DL classes; 4. Online course offers more than $80 \%$ of the content via online delivery [2].

Table 1: Demographics distribution of DL and F2F sections

\begin{tabular}{|l|c|c|c|c|c|c|c|c|c|c|}
\hline & \multicolumn{2}{|l|}{} & Gender & \multicolumn{2}{c|}{ Work } & \multicolumn{2}{c|}{ Age } & \multicolumn{2}{c|}{$\begin{array}{c}\text { Commuting } \\
\text { distance }\end{array}$} & \multicolumn{2}{c|}{$\begin{array}{c}\text { Related } \\
\text { work }\end{array}$} \\
\cline { 2 - 12 } & M & F & $\begin{array}{l}\text { Full- } \\
\text { time }\end{array}$ & $\begin{array}{c}\text { Part- } \\
\text { time }\end{array}$ & $<30$ & $>=30$ & $<10$ & $>=10$ & Yes & No \\
\hline F2F section & 30 & 4 & 12 & 22 & 26 & 8 & 3 & 31 & 7 & 27 \\
\hline $\begin{array}{l}\text { Distance } \\
\text { learning } \\
\text { section }\end{array}$ & 26 & 8 & 17 & 17 & 25 & 9 & 9 & 25 & 10 & 24 \\
\hline
\end{tabular}


A questionnaire was developed to collect students' demographic information. The data includes gender, working status, age, commute distance to campus, and whether their work is related to the course. The data were mapped to the students as part of the analysis.

In both sections, assignments and other course materials were delivered to students using BB. Quizzes were also conducted via BB in both sections. F2F and DL classes had similar assessment evaluation mechanisms. Students in both sections were given identical questions and same amount of time to complete their assessments, and were evaluated by the same instructor using the same grading rubric.

Although there is a huge amount of data available in $\mathrm{BB}$, we were selective in choosing the variables that would possibly have impact on student performance. The variables selected are: time spent completing the assessment, number of times the materials had been accessed, and the time when the students started their assessments.

The course grade was used as an indicator of students' academic performance in the course. It is commonly used as a reliable indicator of how well students meet the course objectives $[4,10]$. The course grade composed of four different components: home assignments, midterm exams, quizzes, and final exam. During the semester, there were 6 home assignments that totaled $30 \%$ of the course grade, two midterm exams, two quizzes which were mix of multiple choice, short answer, and essay questions (30\% weight for two midterms, and $20 \%$ for both quizzes), and the final exam ( $20 \%$ of course grade), which was also a mixture of questions similar to the midterm exams.

Research questions:

A. Is there a correlation between the students' demographics and their performance?

B. How did the students perform in distance learning and F2F sections? Is there a significant difference in the outcome (course grade)?

\section{Analysis and Results}

\section{A. Demographics correlation with course grade}

The data used to determine whether there is a correlation between demographics and performance were accumulated from both sections. The majority of students fell in the following categories: male, living off campus (commute distance more than 15 minutes), less than 30 years old, and has no related work experience with the course. The data was not equally distributed among the demographic variables. To resolve the discrepancy of data distribution, it was normalized and expressed as percentage. Figure 1 shows the different demographic variables and the course grade distribution of each variable. 


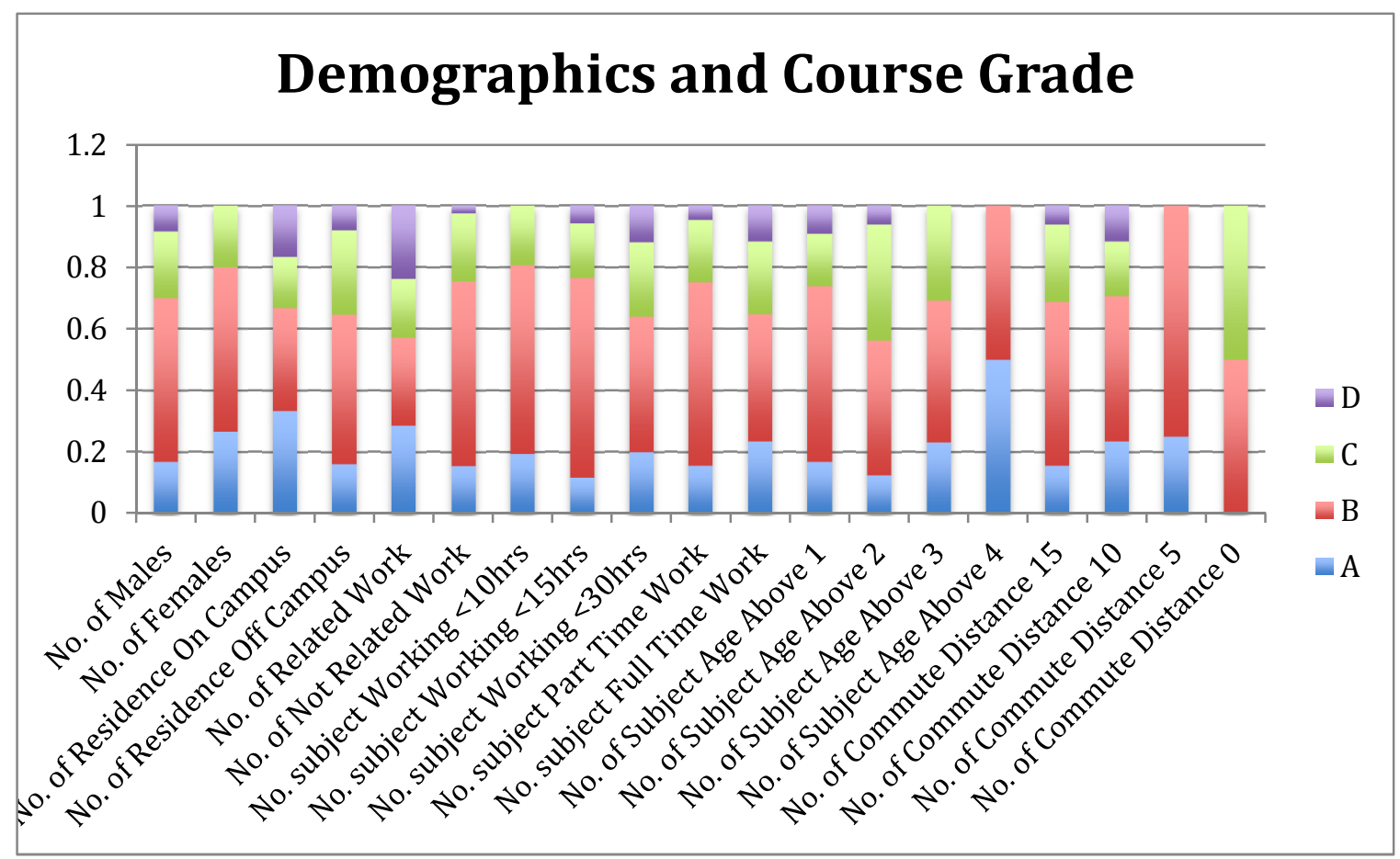

Figure 1: Demographics represented in percentage. The graph shows the percentage of students who earned a course grade of A, B, C, or D of each demographic variable.

The Fisher's exact statistical test was used to analyze the data and find out whether there is a significant relationship between demographic variables and the distribution of course grade. This test was chosen because of the small sample size and the categorical nature of data. In this test, the exact deviation from the null hypothesis is calculated ( $p$-value) rather than relying on approximation.

Table 2 shows the p-value calculation for each demographic variable in its distribution across the course grades (A, B, C, and D). The null hypothesis for each variable: there is no significant relationship between the demographic variable " $\mathrm{x}$ " and the course grade. In other words, the number of subjects for each variable, for example, gender (female, and male), is distributed in the course grade represented by (A, B, C or D). These numbers represent the data to be used in the calculation. The test shows that all demographic variables do not have significant difference between the two groups in their category in terms of their course grade distribution, except related work variable (Table 2). The p-value for "related-work" is 0.00027 , which means there is a significant difference between the students who have related work experience and those who does not. From the data we discovered on average students with related work experience to the course earned a lower course grade. This finding could be due to external factors; future investigation may reveal clearer insights. 
Table 2: Fisher's exact test and p-value of each demographic variable

\begin{tabular}{|l|l|l|}
\hline \multicolumn{1}{|c|}{ Demographic Variable $\mathbf{x}$} & \multicolumn{1}{c|}{ P-value } & \multicolumn{1}{c|}{ Result } \\
\hline Gender (Male, Female) & 0.71 & No significant difference \\
\hline Related work (Yes, No) & 0.00027 & Significantly different \\
\hline Working hours $(<30,>=30)$ hrs & 0.15 & No significant difference \\
\hline Age $(<30,>=30)$ yrs old & 0.42 & No significant difference \\
\hline $\begin{array}{l}\text { Commuting distance }(<10,>=10) \\
\text { miles }\end{array}$ & 0.71 & No significant difference \\
\hline
\end{tabular}

The data collected from Blackboard were based on students' behavior of: the time they started their homework; the time they spent doing it; and the number of times the resource had been visited. Figure 2 shows the correlation between these variables and the course grade. The x-axis represents the course grade, and the $y$ axis represents the time or number after amplification to show the correlation. The study reveals students who received an A grade tend to do the assignment earlier than others. This is inferred from the average time students begin to do the assignment for each group. Moreover, it reveals that there is a correlation between the number of times students access the resource and the course grade. From the graph, we can see the average number of times students access the resource decreases as the student grade deteriorates. Finally, the average time spent on doing the assignment has no correlation with the grade. Majority of the students have the same average time spent on doing the assignment, except for those who do not pass the course.

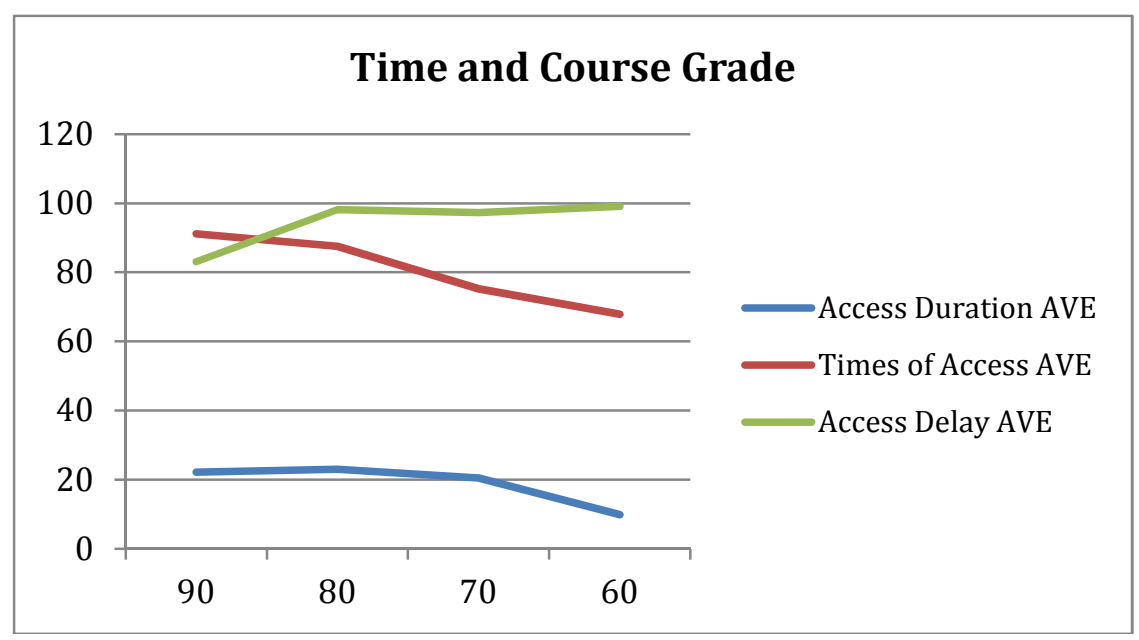

Figure 2: Correlation between the students' behavior in Blackboard and their performance 
To get statistical inferences from the graph, the correlation coefficient was used to determine the relationship between two variables. The correlation coefficient between the grade and the average "\# of times resource accessed" is 0.98, which means there is a strong relationship between the two variable. The student who frequently accessed the resource tends to do a good job in completing the assignment and earn a better grade. The average time spent doing the assignment and the delay time in starting the assignment both show a correlation of 0.83 , and 0.80 respectively.

We also performed a simple linear regression to determine if there was a statistically significant relationship between the three variables and the course grade. Using a significant level $\alpha=0.05$, the $p$-value for the access duration time, access delay time and number of times a resource was accessed were as the following $0.16,0.20$, and 0.02 . Thus, we do not reject the null hypothesis for the first two variables and concluded that there were no significant relationships between the access duration time, or the access delay time and the course grade. However, the test $(\rho$-value $=0.02<\alpha)$ showed that there was a significant relationship between the numbers of times a resource accessed and the course grade.

\section{B. Distance Learning and F2F:}

Due to the small size of data, this section will provide a descriptive observation of the data collected. First, the number of female students in a distance learning class is double the size of females in the F2F class, and there is less number of students who commute more than 10 miles (Table1). Second, there are more students who scored 70 or less (4 students) in the distance learning section as opposed to the F2F section ( 1 student).

On the performance side, F2F students perform better in the final exam, quizzes and midterm exams in comparison with their counterparts in the distance learning class. On the same token, DL students did better in their average homework, particularly the students with 80 or below course grade. Figure 3 and Table 3 reveals this information.
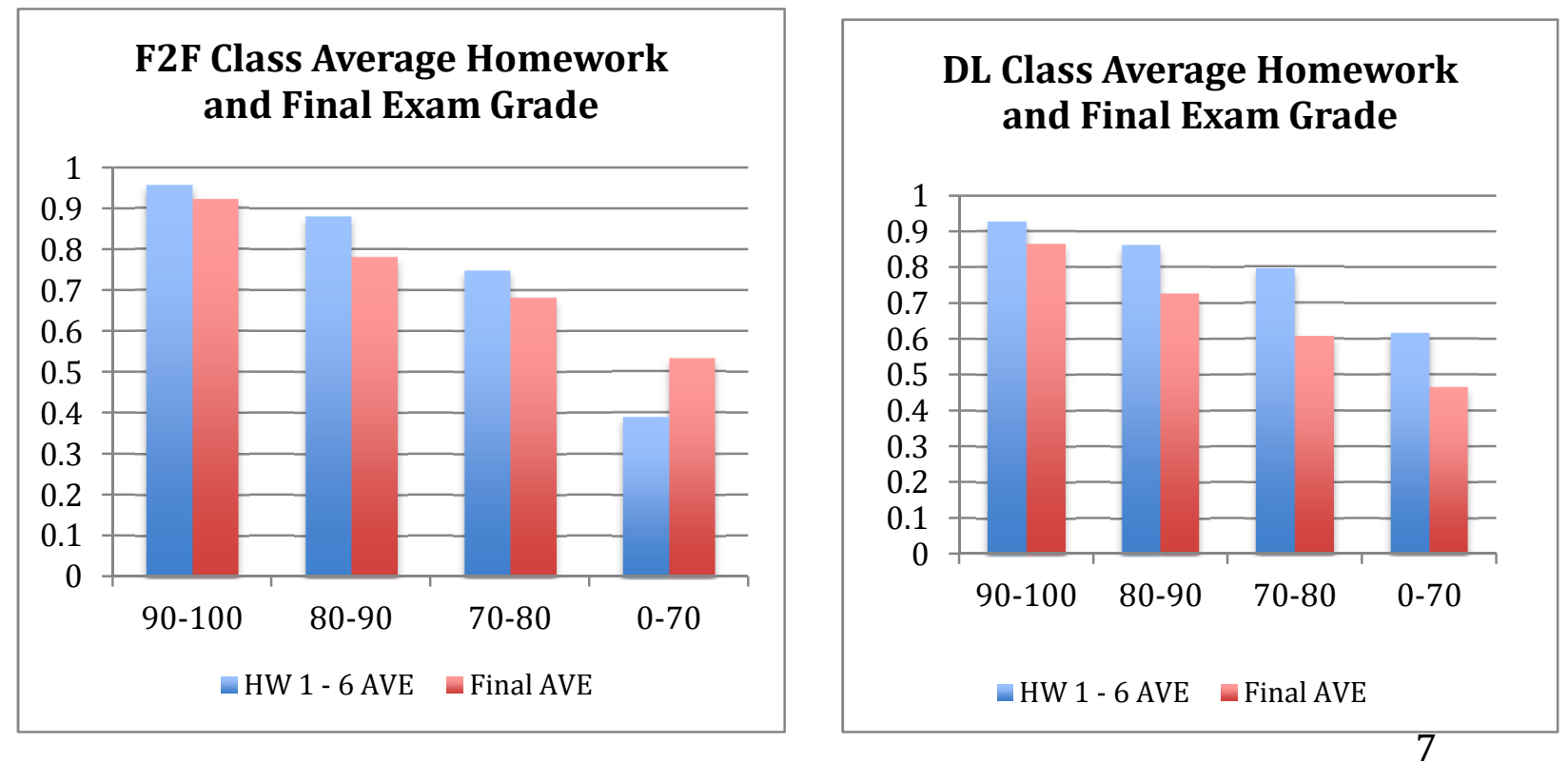
Figure 3: Comparison of Average Homework and Final Exam grades in both sections

Another observation of both classes: students who are 30 years or older have similar performance with quizzes and final exam. In both sections, we observed students who are 30 year old (the common variable) doing poorly with their quizzes but earning better grades in their final exam. This is contradictory because students in general, perform the best in assignment, then quizzes and least in the final exam.

Table 3 shows the two classes are significantly different with course grade, but not the final exam, assignments, quizzes, or midterms grades (A, B, C and D). In other words, the distribution of students who earned $A, B, C$ or D is significantly different with the overall course grade (4-A, 15-B, 14-C, and 1-D) in F2F while in distance learning class the distribution of students is $(8-\mathrm{A}, 17-\mathrm{B}, 4-\mathrm{C}, 5-\mathrm{D})$. Although the number of students in the distance learning section who received A grade is higher, it is also true that the number of them earning D grades is higher.

Table 3: Fisher's exact test results for the assessment variable and their relationship with the distribution of the students in terms of their overall course grade

\begin{tabular}{|l|l|l|}
\hline \multicolumn{1}{|c|}{ Assessment x } & \multicolumn{1}{|c|}{ P-value } & \multicolumn{1}{c|}{ Result } \\
\hline Course grade & 0.0188 & Significantly different \\
\hline Final exam & 0.3268 & No significant difference \\
\hline Average Homework & 0.521 & No significant difference \\
\hline Average quizzes & 0.267 & No significant difference \\
\hline Midterm1 & 0.475 & No significant difference \\
\hline Midterm2 & 0.999 & No significant difference \\
\hline
\end{tabular}

When comparing the two classes, the mean and standard deviation (SD) were used to perform the t-test. Table 4 shows the mean and SD for each assessments used in the class. The result shows the difference between the two classes. DL class outperform F2F class in terms of its average homework scores, however, F2F class outperform DL with the remaining assessments.

Table 4: The mean and standard deviation of each assessment in both sections

\begin{tabular}{|l|c|c|c|c|c|}
\hline \multicolumn{7}{|c|}{ F2F Class } \\
\hline Mean & $\begin{array}{c}\text { AVG HW } \\
\text { Grade }\end{array}$ & $\begin{array}{c}\text { AVG Quiz } \\
\text { Grade }\end{array}$ & $\begin{array}{c}\text { AVG Midterm } \\
\text { Grade }\end{array}$ & $\begin{array}{c}\text { Final Exam } \\
\text { Grade }\end{array}$ & $\begin{array}{c}\text { Course } \\
\text { Grade }\end{array}$ \\
\hline SD & 81.73 & 81.19 & 76.80 & 75.24 & 82.71 \\
\hline \multicolumn{7}{|c|}{ DL Class } & 0.10 & 0.11 \\
\hline Mean & 0.13 & 0.16 & 76.24 & 69.44 & 81.81 \\
\hline SD & 83.96 & 80.05 & 0.15 & 0.21 & 0.12 \\
\hline
\end{tabular}




\section{Conclusion and Limitations}

The study shows the following: there is no evidence found for student demographics independently having a relationship with the student's performance (course grade), except the students who have related work experience; their performance was worse when compared to those who do not have related work experience (based on their overall course grade average). Blackboard data also shows the correlation between student's behaviors in LMS and their grade. The time spent doing an assessment, the time when students start their assessment, and the number of times students access the resource all have a strong correlation with the student grade. Finally, F2F students statistically, significantly outperform distance learning students with their overall course grade. However, both classes in this study obtain similar grades in all the assessments.

\section{Limitations}

Our sample is too small to consider all the demographic variables along with the performance to derive at more accurate inference. The combination of more than 6 variables may result in a large number of groups. If we assumed 6 variables and each variable had 2 options (values), then we may end up with 64 different combinations of groups. This is why 100 or 200 subjects are considered quite small to make solid conclusive inferences. If the same course were taught multiple times using the same settings, it would be easier to generalize the findings.

\section{References}

1. Agdas, D., Washington, S., Ellis, R. D., Agdas, S., \& Dickrell, P. (2013). Analysis of Distance Learner Value Assessment of Distance Education in Engineering. Journal of Professional Issues in Engineering Education \& Practice, 140(1).

2. Allen, I. E., \& Seaman, J. (2013). Changing Course: Ten Years of Tracking Online Education in the United States. Babson Survey Research Group and the Sloan Consortium. Available: http://files.eric.ed.gov/fulltext/ED541571.pdf

3. Bernard, R. M., Abrami, P. C., Lou, Y., Borokhovski, E., Wade, A., Wozney, L., ... \& Huang, B. (2004). How does distance education compare with classroom instruction? A meta-analysis of the empirical literature. Review of educational research, 74(3), 379-439.

4. Driscoll, A., Jicha, K., Hunt, A. N., Tichavsky, L., \& Thompson, G. (2012). Can online courses deliver in-class results? A comparison of student performance and satisfaction in an online versus a face-to-face introductory sociology course. Teaching Sociology, 40(4), 312-331.

5. Duffy, T., Gilbert, I., Kennedy, D., \& Kwong, P. W. (2002). Comparing distance education and conventional education: observations from a comparative study of post-registration nurses. Research in Learning Technology, 10(1).

6. Johri, A., Teo, H. J., Lo, J., Dufour, M. \& Schram, A. (2014). Millennial Engineers: Digital Media and Information Use Among Engineering Students. Computers in Human Behavior, 33: 286-301. 
7. Means, B., Toyama, Y., Murphy, R., Bakia, M., \& Jones, K. (2009). Evaluation of Evidence-Based Practices in Online Learning: A Meta-Analysis and Review of Online Learning Studies. US Department of Education.

8. Russell, T. L. (1999). The no significant difference phenomenon: a comparative research annotated bibliography on technology for distance education : as reported in 355 research reports, summaries and papers. North Carolina State University.

9. Shachar, M., \& Neumann, Y. (2010). Twenty years of research on the academic performance differences between traditional and distance learning: Summative metaanalysis and trend examination. MERLOT Journal of Online Learning and Teaching, 6(2).

10. Suskie, L. (2004). Assessing student learning: A common sense guide. Bolton, Mass.: Anker

11. Tamim, R. M., Bernard, R. M., Borokhovski, E., Abrami, P. C., \& Schmid, R. F. (2011). What forty years of research says about the impact of technology on learning a second-order meta-analysis and validation study. Review of Educational Research, $81(1), 4-28$

12. Urtel, M. G. (2008). Assessing Academic Performance between Traditional and Distance Education Course Formats. Educational Technology \& Society, 11(1), 322330. 